- There are specific requirements for design to obtain aesthetics.

- Cement margin location is critical for long term outcome.

- Abutment material selection must balance aesthetics and function.

- Retrieval of the cemented restorations is important for long term maintenance.

\title{
Designing abutments for cement retained implant supported restorations
}

\author{
W. Chee ${ }^{1}$ and S. Jivraj ${ }^{2}$
}

\author{
In another article in this series the authors' preference for screw retained implant supported restorations was presented \\ together with a literature review and rationale. ${ }^{1}$ There remain situations when screw retention is not possible due to implant \\ position, implant trajectory, aesthetics or function.
}

\begin{tabular}{|c|}
\hline IMPLANTS \\
\hline 1. Rationale for dental implants \\
\hline $\begin{array}{l}\text { 2. Treatment planning of implants in } \\
\text { posterior quadrants }\end{array}$ \\
\hline $\begin{array}{l}\text { 3. Treatment planning of implants in } \\
\text { the aesthetic zone }\end{array}$ \\
\hline $\begin{array}{l}\text { 4. Surgical guidelines for dental } \\
\text { implant placement }\end{array}$ \\
\hline $\begin{array}{l}\text { 5. Immediate implant placement: } \\
\text { treatment planning and surgical steps } \\
\text { for successful outcomes }\end{array}$ \\
\hline $\begin{array}{l}\text { 6. Treatment planning of the } \\
\text { edentulous maxilla }\end{array}$ \\
\hline $\begin{array}{l}\text { 7. Treatment planning of the } \\
\text { edentulous mandible }\end{array}$ \\
\hline $\begin{array}{l}\text { 8. Impressions techniques for implant } \\
\text { dentistry }\end{array}$ \\
\hline $\begin{array}{l}\text { 9. Screw versus cemented implant } \\
\text { supported restorations }\end{array}$ \\
\hline $\begin{array}{l}\text { 10. Designing abutments for } \\
\text { cement retained implant supported } \\
\text { restorations }\end{array}$ \\
\hline 11. Connecting implants to teeth \\
\hline $\begin{array}{l}\text { 12. Transitioning a patient from teeth } \\
\text { to implants }\end{array}$ \\
\hline $\begin{array}{l}\text { 13. The role of orthodontics in implant } \\
\text { dentistry }\end{array}$ \\
\hline $\begin{array}{l}\text { 14. Interdisciplinary approach to } \\
\text { implant dentistry }\end{array}$ \\
\hline $\begin{array}{l}15 . \text { Factors that affect individual } \\
\text { tooth prognosis and choices in } \\
\text { contemporary treatment planning }\end{array}$ \\
\hline 16. Maintenance and failures \\
\hline
\end{tabular}

Off axis implant placement can sometimes be compensated with angled abutments that still allow screw retention. For these angled abutments to be used the angle compensation must be more than 17 degrees (Figs 1-2). This is to allow sufficient divergence in the trajectory of the abutment screw to still allow housing for the retentive screw of the restoration. If the divergence of the implant axis and the retaining screw of the abutment to receive the restoration is less than 17 degrees, there remains insufficient bulk of the abutment to house the retaining screw of the restoration (Fig. 3). In these situations conventional screw retention of restorations is not possible. Lingual set screws can be incorporated in order to retain restorations on, essentially, abutments designed for cement retention, but these are technically challenging to execute

\footnotetext{
1"Ralph W. and Jean L. Bleak Professor of Restorative Dentistry, Director of Implant Dentistry at the University of Southern California School of Dentistry / Private Prosthodontics Practitioner, Pasadena, California; ${ }^{2}$ Chairman, Section of Fixed Prosthodontics and Operative Dentistry, University of Southern California School of Dentistry / Private Prosthodontics Practitioner, Burbank, California

*Correspondence to: Dr Winston Chee, School of Dentistry, Rm. 4374 University Park, University of Southern California, Los Angeles, CA 90089-0641, USA Email:wchee@usc.edu
}

\section{Refereed Paper}

๑ British Dental Journal 2006; 201: 559-563

DOI: $10.1038 / \mathrm{sj} .6 d j .4814205$
(Figs 4-5). Alternative methods to displace cemented implant restorations have also been described. One design used screws to displace cemented crowns by pushing against abutments. ${ }^{2}$ Abutments for this type of restoration were designed to receive cemented restorations, screws were incorporated into the restorations, and when needed the screws were activated to lift restorations off abutments. Figure 6 illustrates a casting for this type of restoration; note the threads incorporated into the restoration. Figures 7 and 8 illustrate how the screw works to lift the restoration off the abutment when activated; note that it pushes against the abutment and can be placed in almost any location as long as it has a displacing force. Figures 9 and 10 show intraoral occlusal and facial views of the restoration , the displacement screw can be placed in the most ideal position without regard to implant position.

Though other methods have been developed to retrieve cemented restorations, the ideal abutment design should still have the following characteristics:

1. The cement margin should follow the mucosal outline

2. The material of the abutment should be strong in thin section

3. The material should be biocompatible.

\section{Cement margin}

Abutments to receive cemented implant restorations can be largely classified as stock or 
Fig. 1 Master cast with implant trajectory exiting in an aesthetic area which will require redirection of restoration retaining screw axis.

Fig. 2 Master cast with angled abutment in place illustrating change in restoration retaining screw trajectory.

Fig. 3 When the divergence is less than approximately 17 degrees the occlusal portion of the abutment is obliterated, there is no housing available for the secondary screw (left abutment). The right abutment has sufficient divergence and can house a retaining screw.

Fig. 4 Lingual set screw used to retain restorations when cement retention was avoided.
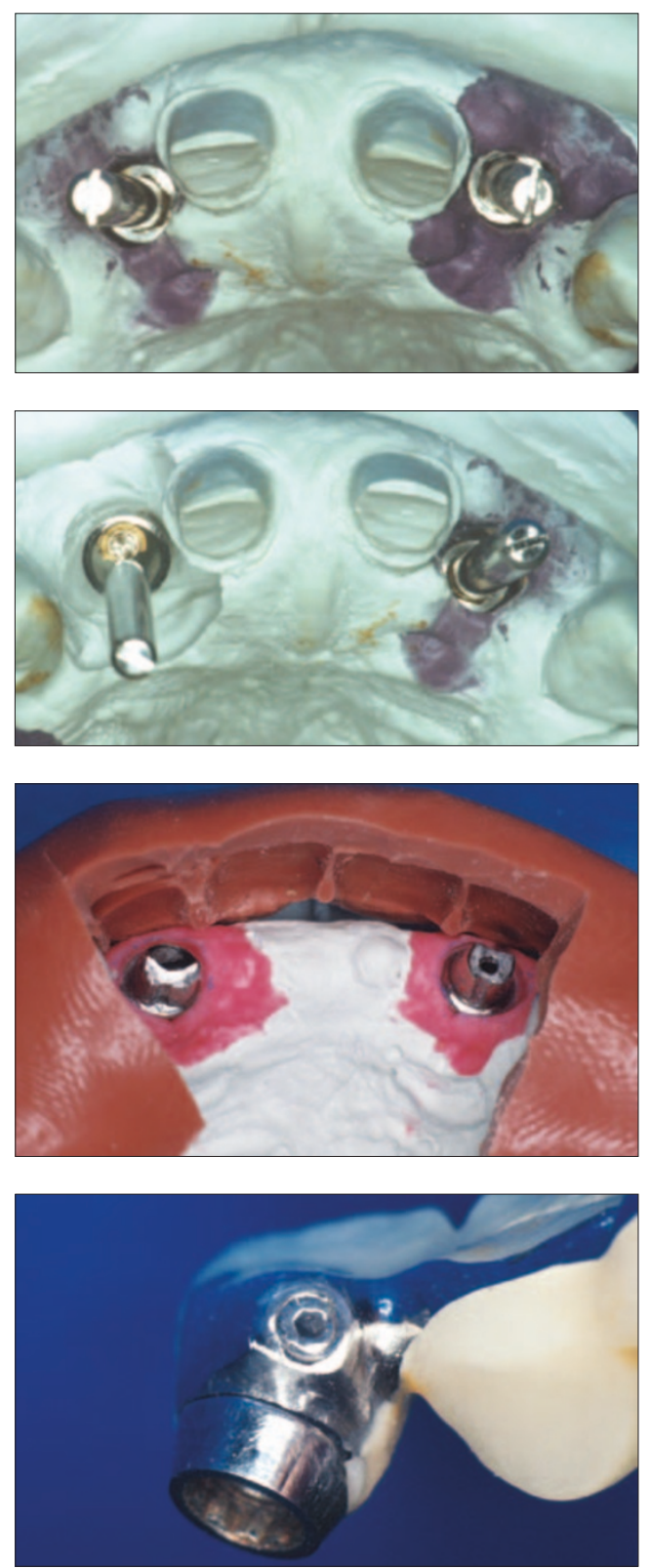

Fig. 5 Intra-oral view of set screw being engaged.

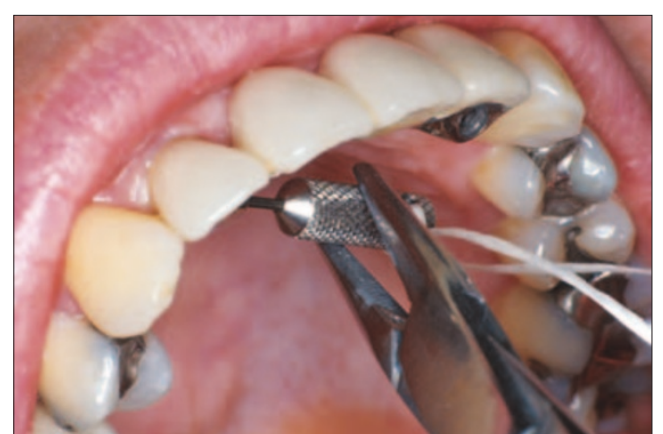

custom abutments. Stock abutments are fabricated by manufacturers and the cement margin and profile of the abutment are either made to average dimensions or ignored entirely. Figure 11 is a diagrammatic representation of stock abutment; note that the margins are without scallop and are circular; there is no regard to the mucosal levels. This leads to potential problems of cement retention and difficult management of soft tissues. As described in another article in this series (Treatment planning of implants in the aesthetic zone. BDJ 2006; 201: 77-89), the ideal implant position to obtain an aesthetic outcome will be located $3 \mathrm{~mm}$ or more below the buccal mucosal margin. When there is any scallop this can lead to the margin being 5-6 $\mathrm{mm}$ sub-muscosal in the interproximal areas. Figure 12 illustrates a stock abutment on a soft tissue cast with a periodontal probe indicating the distance from the peak of the scallop to the cement margin being $6 \mathrm{~mm}$. Figure 13 illustrates the typical form of a cemented restoration made for this type of abutment - note the form of the margin which conforms to the abutment margin. This deep margin leads to two clinical problems: maintaining the soft tissue profile while the restoration is removed, and cement removal after cementation. Figure 14 is an intra oral view of a stock abutment; note the deep cement margin in the interproximal area. A provisional restoration has been removed; note that the tissue profile is held by the restoration and not the by the abutment. If the restoration was not replaced within a short period the soft tissue would rapidly collapse around the abutment (Fig. 16). In addition, cement can be seen at the restoration abutment interface. It has been demonstrated that removing this cement in deep sub-mucosal areas is difficult if not impossible. ${ }^{3}$ The use of stock abutments should be used only when minimal scallop of the mucosal margins are present and cement margins can be kept within 2-3 $\mathrm{mm}$ of the cement margin or stock abutments with supra-muscosal margins to be modified, to adapt more closely to mucosal margins to facilitate cement removal.

Custom abutments are either waxed on to machined cylinders to form and cast or machined from titanium via a computer aided design (3i Encode, Nobelbiocare Procera, Zimmer Dental, Atlantis Abutments), or copied from a waxed form (Nobelbiocare Procera). When custom abutments are designed with support of the soft tissue and cement margin location in mind, most of the problems of cementation with stock abutments can be overcome. Figure 16 is a diagrammatic depiction of how an abutment should be designed, with the cement margin following the mucosal outline and the abutment flaring from implant to the exit profile to support the soft tissue. The soft tissue should remain in place though the restoration is removed. Figure 17 illustrates how the abutment flares to support soft tissue and the cement margin is customised to the intra-oral soft tissue levels. Figure 18 demonstrates how the abutment supports the soft tissue and the cement margin is readily accessible for cement removal post cementation (compare with Figs 14-15).

\section{Strength of the abutment}

The ideal abutment should be tooth coloured this will allow ideal soft tissue colouration and the best opportunity for aesthetics, as all ceramic restorations can be used. At present alumina or zirconia abutments are available. It must be kept in mind that when the abutment 


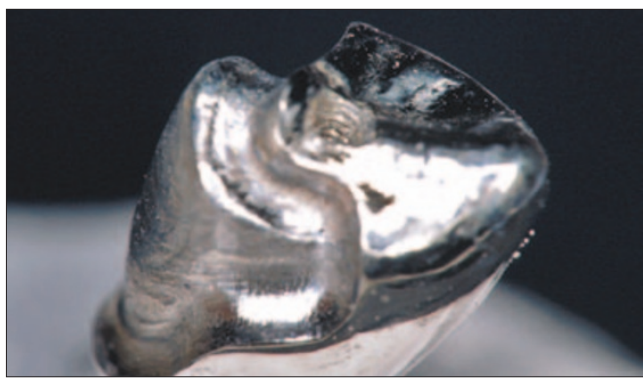

Fig. 6 Casting with screw thread incorporated into occlusal surface.

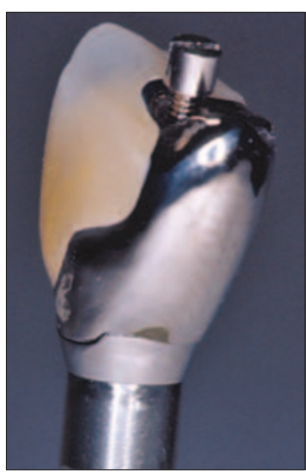

Fig. 7 Casting in Figure 6 with ceramic applied on custom abutment with removal screw passive.

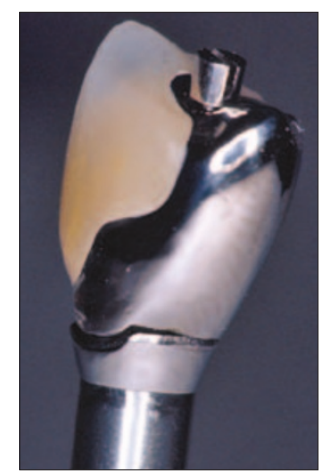

Fig. 8 Restoration in Figure 7 with removal screw activated - lifting restoration off the abutment.

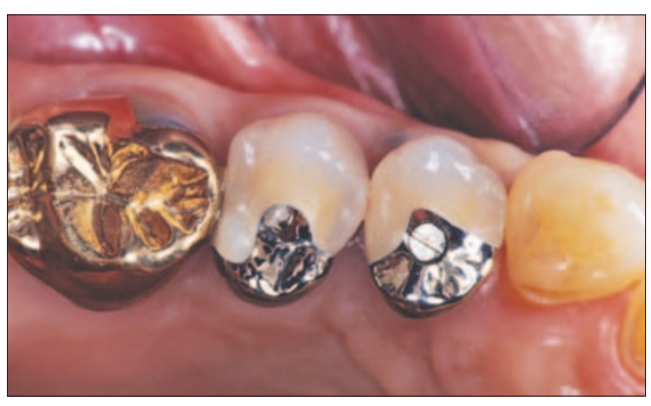

Fig. 9 Occlusal view of restoration intra-oral - note that the screw can be placed in any position where it can exert a displacing force. The axis of the implant can be ignored.

retaining screw access and angle correction are taken into account, the resulting abutments are often left with very thin sections (Fig. 19). These abutments are at risk of fracture due to these dimensions. Moreover, porcelain fails with crack propagation, and tensional forces in a wet environment encourage these cracks to enlarge leading to failure. The stress of the abutment screw when tightened contributes to these tensional forces. When breakage occurs patients will require immediate attention, especially in aesthetic areas. With a delay of more than a few hours the soft tissue will have closed over the implant. These unscheduled appointments are difficult to manage and the costs to replace the restorations are high (Fig. 20). Figure 21 is an intra-oral view of an acrylic abutment made and placed immediately to support a provisional restoration for the fractured abutment in Figure 20. It is the authors' recommendation

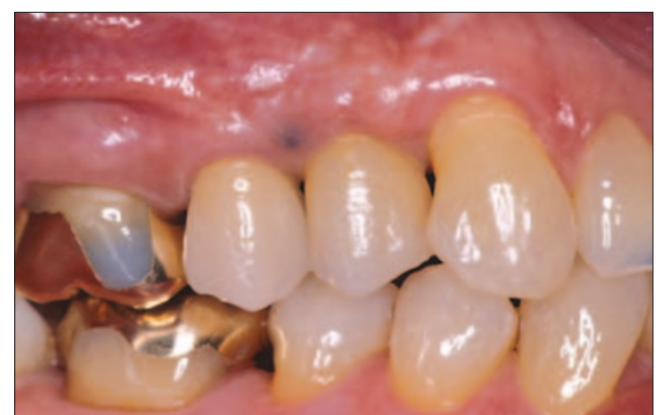

Fig. 10 Buccal view of restoration.

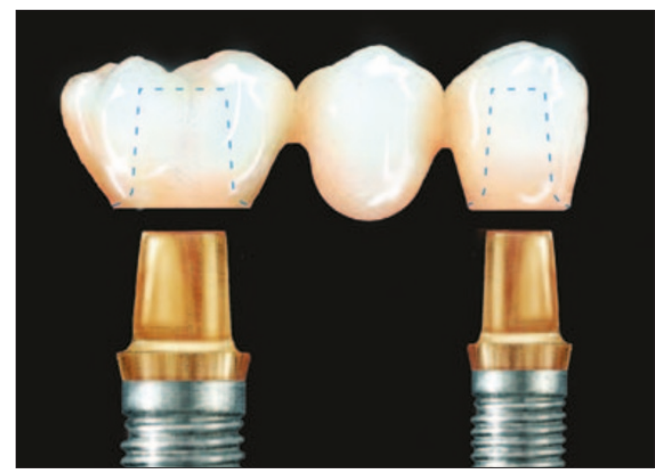

Fig. 11 Diagram of stock abutments, cement margins are circular and without scallop.

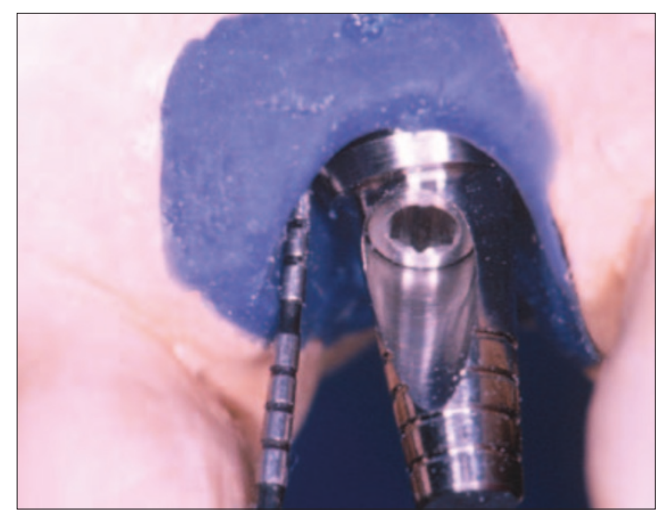

Fig. 12 Angled stock abutment in place. The buccal margin is too high and the interproximal margin is too deep.

that ceramic abutments only be used in narrow indications, when soft tissues are thin and abutment colour will show through or when teeth are highly translucent and all ceramic restorations are required to allow a good match. The restorations with ceramic abutments should be limited to single units, keeping in mind that they may fracture and require remaking the restoration. If multiple unit splints were built on ceramic abutments, a fracture of one abutment would cause failure of the entire splint. Another consideration is the management of ceramic abutments in the event of screw loosening. With metallic abutments restorations can sometimes be removed with pneumatic back action devices (Kavo coronoflex) and abutment screws can be re-torqued and restorations re-cemented. Use of these impact devices will cause fracture of the all ceramic restorations and their abutments.

With thin tissues and show through of the 
Fig. 13 Restoration for stock abutment. Note the circular cement margin and the flare of the restoration to support soft tissue profiles.

Fig. 14 Intra-oral view of stock abutment - note deep cement margins.

Fig. 15 Occlusal view of abutment in Figure 14; note cement retention from provisional restoration.

Fig. 16 Diagram of how a custom abutment should flare from implant to the exit profile and the cement margin should follow the mucosal margins.
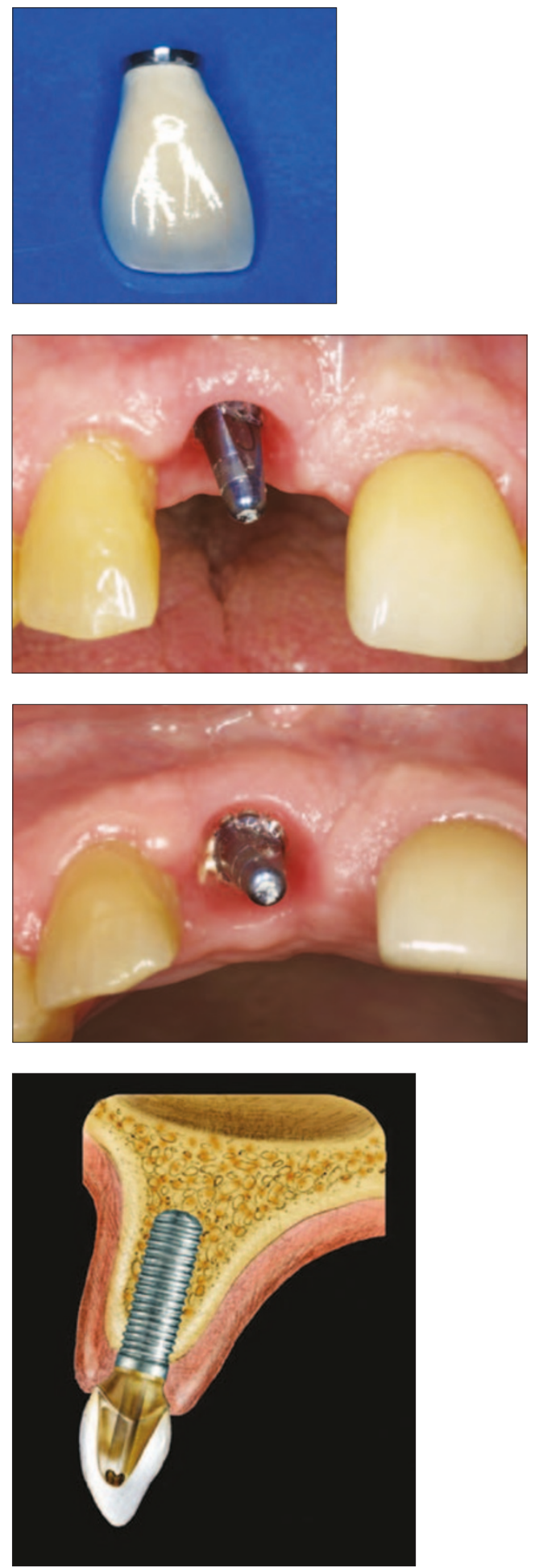

Fig. 17 An extra-oral view of a cast gold custom abutment and restoration, note the flare of the abutment and the conforming margin.

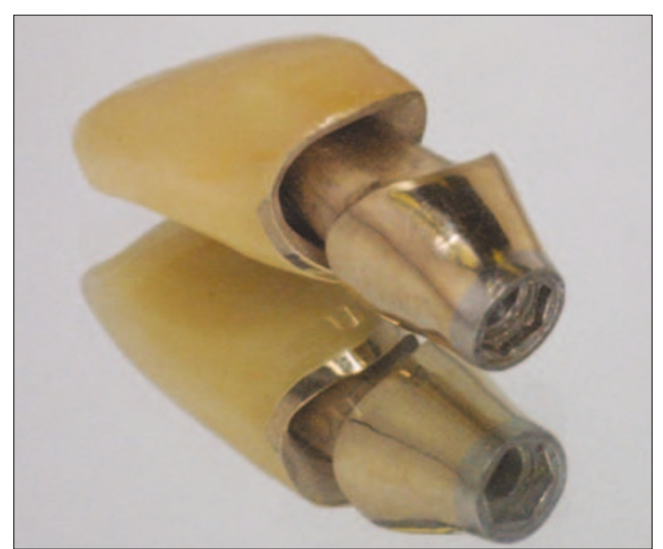

abutment, colour is an issue; an alternative to all ceramic abutments is to have porcelain fired onto the labial portion of an abutment that has been cast in a metal ceramic alloy (Fig. 22). Care must be taken to ensure that during fabrication stages of this type of abutment, there is a layer of wax over the machined restorative cylinder, so that a metal ceramic alloy will be available to enamel porcelain to. The machined cylinders in general are not receptive to porcelain bonding.

\section{Biocompatibility}

There are some animal studies which have indicated that the most compatible materials to soft tissue are alumina and machined titanium. ${ }^{4}$ Another study by the same authors also found that abutments once in place should be left in place. Insertion and removal of the abutment has the potential to alter soft tissue levels and this may have an impact on the aesthetic outcome. ${ }^{5,6}$ While these findings should be kept in mind and these two materials have been shown to be suitable materials with respect to biocompatibility, the weakness of alumina has been discussed and the grey colour of machined titanium can cause discolouration of the tissues. Figure 23 is an intra-oral view of a titanium abutment made for the restoration in Figures 20 and 21. Note how a ceramic abutment has the drawback of potential fracture and the titanium abutment has the potential to discolour tissue.

Gold custom abutments seem to be the best compromise at present; yellow gold is strong in thin section and can be cast easily to form, and gold has a long record in dentistry of biocompatibility. Unless special circumstances are present, the gold custom abutment designed to support the soft tissue exit and follow the mucosal margin is most often chosen when screw retention is contra-indicated (Figs 18-19).

Recently, several implant manufacturers ( $3 i$, Atlantis) that offer custom abutments machined out of titanium have advertised the capability of coating titanium abutments with titanium nitride. This will give a golden hue to the abutment and should improve the aesthetics of the soft tissues when titanium abutments are used. Other colours are also available with this coating and it would be interesting to observe the effects of different coatings with respect to soft tissue discolouration. For example a pink hue might be better than a golden hue for aesthetics.

\section{CONCLUSIONS}

Discussion regarding the advantages and disadvantages of screw vs cemented implant supported restorations were elucidated in a previous article (Screw versus cemented implant supported restorations. BDJ 2006; 201: 501507). This article describes concepts to design abutments to receive cemented implant restorations. Ideally a custom abutment should be biocompatible, promote soft tissue attachment to the abutment, be tooth coloured, be strong, have adequate retention and resistance form, support soft tissue, allow cement removal and 


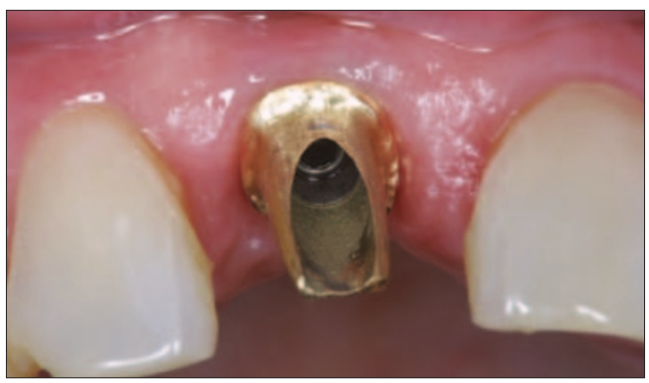

Fig. 18 Intra-oral view of custom abutment in place, note the soft tissue support provided by the abutment and the location of the margin for cement removal.

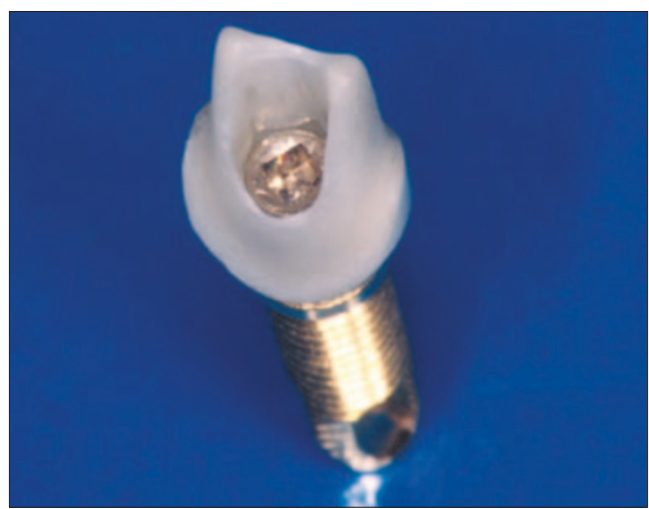

Fig. 19 A ceramic abutment, note thin walls of the abutment to accommodate the retaining screw.

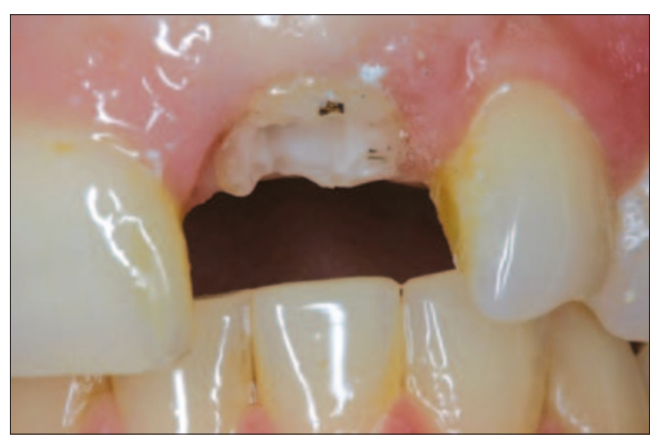

Fig. 20 Intra-oral view of fracture abutment - note that tissue colour is not discoloured by the ceamic abutment.

have a machine fit to the implant. There is at present no abutment that fulfills all these 'ideal' criteria. The most versatile abutment material available is gold cast to machined implant cylinders. Machined titanium abutments are available from manufacturers; however, the silver colour can discolour tissues when they are thin. In addition, these machined abutments are not universally available for all implant systems. Coating these abutments with titanium nitride can mitigate this discolouration and make machined titanium abutments that fulfill all the criteria discussed more acceptably. Ceramic abutments should be used sparingly due to the potential for breakage.

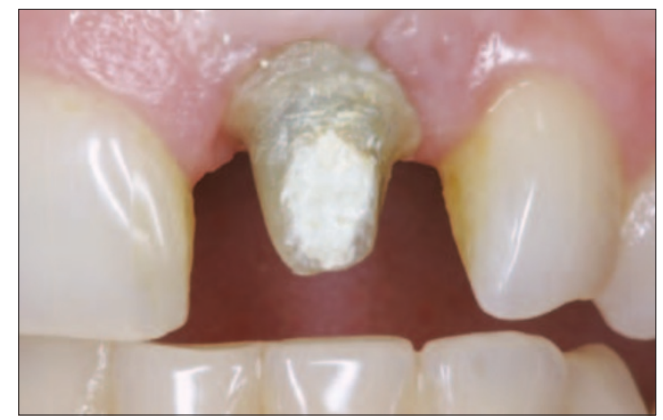

Fig. 21 Provisional abutment made from acrylic resin for patient in Figure 20 adapted to a provisional cylinder to support provisional restoration; note that tissue colour is acceptable.

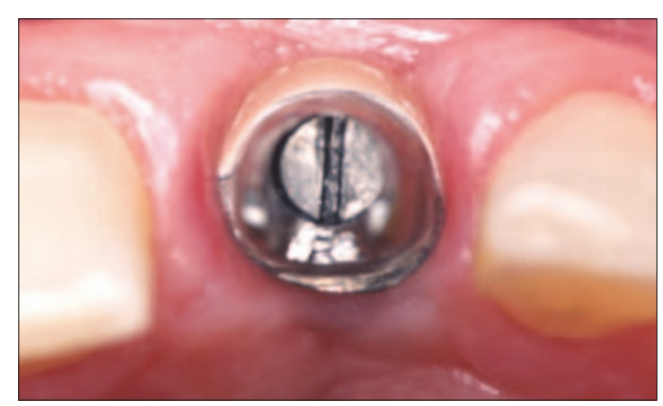

Fig. 22 A metallic abutment with porcelain fired to the buccal surface to prevent tissue discolouration.

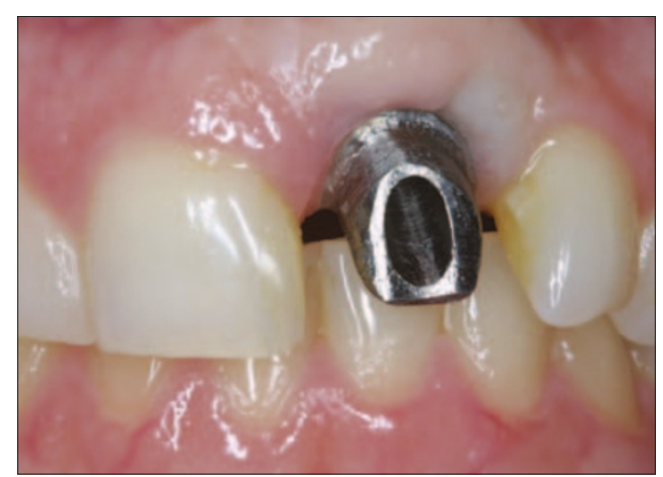

Fig. 23 Titanium abutment made for patient in Figure 20; the tissue colour is unacceptable.

1. Chee W, Felton D A, Johnson P F, Sullivan D Y. Cemented versus screw-retained implant prostheses: which is better? Int J Oral Maxillofac Implants 1999; 14: 137-141.

2. Chee W W, Torbati A, Albouy J P. Retrievable cemented implant restorations. J Prosthodont 1998; 7: 120-125.

3. Agar J R, Cameron S M, Hughbanks J C, Parker M H. Cement removal from restorations luted to titanium abutments with simulated subgingival margins. J Prosthet Dent 1997; 78: 43-47.

4. Abrahamsson I, Berglundh T, Glantz P O, Lindhe J. The mucosal attachment at different abutments. An experimental study in dogs. J Clin Periodonto/ 1998; 25: 721-727.

5. Abrahamsson I, Berglundh T, Sekino S, Lindhe J. Tissue reactions to abutment shift: an experimental study in dogs. Clin Implant Dent Relat Res 2003; 5: 82-88.

6. Abrahamsson I, Berglundh T, Lindhe J. The mucosal barrier following abutment dis/reconnection. An experimental study in dogs. J Clin Periodontol 1997; 24: 568-572. 